\title{
Canaries in the Goal Mines: A Timely Analysis of College Athletics and the Role of Student-Athletes
}

\author{
C. Keith Harrison \& Scott Bukstein \\ University of Central Florida
}

In July 2012, the National Collegiate Athletic Association (NCAA) imposed severe sanctions on The Pennsylvania State University (Penn State) athletics program related to allegations of sexual abuse occurring in Penn State athletics facilities. Sanctions included a $\$ 60$ million fine, a four-year postseason ban for the Penn State football team, a significant reduction in athletics scholarships, and a fiveyear probationary period (Consent Decree, 2012). These punitive actions were designed in part to "change the culture that allowed this activity to occur and realign it in a sustainable fashion with the expected norms and values of intercollegiate athletics" (Consent Decree, 2012, p. 4). The NCAA concluded that the situation at Penn State demonstrated "an unprecedented failure of institutional integrity leading to a culture in which a football program was held in higher esteem than the values of the institution, the values of the NCAA, the values of higher education, and most disturbingly the values of human decency" (Consent Decree, 2012, p. 4).

Reactions to the penalties were mixed among those associated with the university. Rodney Erickson, then President at Penn State, stated that the university accepted the NCAA penalties and corrective actions. Erickson explained that Penn State:

must create a culture in which people are not afraid to speak up, management is not compartmentalized, [and] all are expected to demonstrate the highest ethical standards... [w] e continue to recognize the important role that intercollegiate athletics provides for our student athletes and the wider University community as we strive to appropriately balance academic and athletic accomplishments (Erickson Statement, 2012).

However, some Penn State stakeholders did not support the NCAA sanctions against the university. For example, shortly after the NCAA announced the sanctions, members of the Penn State Board of Trustees as well as the Governor

The authors are with the College of Business Administration, DeVos Sport Business Management Program, University of Central Florida, Orlando, FL. Address author correspondence to Scott Bukstein at scott.bukstein@ucf.edu. 
of Pennsylvania challenged the validity and enforceability of the Consent Decree and corresponding sanctions (Notice of Appeal, 2012; Corbett v. NCAA, 2013).

At the time of publication of this essay, litigation is ongoing with respect to how and where the $\$ 60$ million in fine money will be used. In addition, in September 2014 the NCAA Executive Committee eliminated Penn State's postseason ban and returned all athletics scholarships due to Penn State's "significant progress toward ensuring its athletics department functions with integrity" (Hosick, 2014a; Mitchell Report, 2014). Then, in November 2014 the NCAA was required to release a series of internal e-mails between NCAA leaders during the discovery (i.e., informationgathering) phase of the above-mentioned lawsuit related to the $\$ 60$ million fine (Corman v. NCAA, 2014). Several of these e-mails indicate that senior NCAA officials questioned the NCAA's jurisdiction (i.e., authority) to impose the sanctions against Penn State. For example, former NCAA Vice President of Enforcement Julie Roe Lach characterized the overall NCAA approach as a "bluff" to pressure Penn State to accept the sanctions. Roe Lach acknowledged the NCAA "could try to assert jurisdiction on this issue and may be successful but it'd be a stretch" (personal communication, July 14, 2012). Roe Lach's e-mail was in response to questions posed by her colleague Kevin Lennon, NCAA Vice President of Academic and Membership Affairs. Lennon wrote "I know we are banking on the fact [that the] school is so embarrassed they will do anything, but I am not sure about that . .. This will force the jurisdictional issue [and] we really don't have a great answer to that one" (personal communication, July 14, 2012).

The NCAA responded to the release of the e-mails with the following justification and rationale:

Debate and thorough consideration is central in any organization, and that clearly is reflected in the selectively released emails. The national office staff routinely provides information and counsel to the membership on tough issues. The NCAA carefully examined its authority and responsibility to act (NCAA Press Release, 2014).

Penn State also issued a statement regarding the NCAA e-mails, in which current Penn State President Eric Barron and Chairman of the Board of Trustees Keith Masser stated:

We find it deeply disturbing that NCAA officials in leadership positions would consider bluffing one of their member institutions, Penn State, to accept sanctions outside of their normal investigative and enforcement process. We are considering our options. It is important to understand, however, that Penn State is in the midst of a number of legal and civil cases associated with these matters (Penn State Press Release, 2014).

\section{Another Look at the Consent Decree and Its Impact}

Given this background, it is useful to revisit the July 2012 Consent Decree in which the NCAA focused on the lack of institutional integrity at Penn State as well as the need for Penn State to change its culture to realign the university athletics program with the norms and values of intercollegiate athletics. The flawed communication 
and enforcement process throughout the Penn State situation is only one example of numerous recent situations involving the NCAA that have resulted in widespread criticism about the institutional integrity, culture, and values of the NCAA.

For example, in 2013 the NCAA uncovered an issue of improper conduct within its internal enforcement program that occurred during an investigation of the University of Miami athletics program (NCAA, 2013). The NCAA hired a law firm to conduct an external review of the NCAA's own internal enforcement program. An extensive report by the law firm concluded that the NCAA enforcement staff "had paid a source's attorney to insert herself into an ongoing bankruptcy proceeding and to use its subpoena power to compel depositions from uncooperative witnesses" (Wainstein et al., 2013). The authors of the report recognized that this incident "raised understandable doubts in the minds of many about the management, integrity and effectiveness of the NCAA's Enforcement operations" (Wainstein et al., 2013). NCAA President Mark Emmert addressed this situation: "To say the least, I am angered and saddened by this situation. Trust and credibility are essential to our regulatory tasks. My intent is to ensure our investigatory functions operate with integrity and are fair and consistent with our member schools, athletics staff and most importantly our student-athletes" (NCAA, 2013).

The Penn State and University of Miami situations have called into question the credibility, accountability and sustainability of the NCAA, and have created some uncertainty about the continued viability of the current college athletics model. The actions of NCAA leaders and the policies established by the NCAA directly impact the priorities of its member institutions as well as the perspectives and perceptions of its student-athletes. For example, member institutions in the "Power 5" NCAA conferences (i.e., Big Ten, Pac-12, Big 12, SEC, and ACC) have requested greater autonomy to make important decisions on student-athlete wellbeing issues such as transfer rules, length of athletic scholarships and medical insurance coverage. And, recent situations involving controversial-and arguably contradictory-studentathlete suspensions related to accepting cash for autographed memorabilia (e.g., the Todd Gurley situation at University of Georgia) and athletic departments deciding not to renew athletic scholarships of student-athletes because NCAA rules merely require schools to offer one-year scholarships (for example, the James Grisom situation at University of California, Berkeley) have produced "role conflict" for student-athletes as they attempt to navigate their academic and athletic identities (Sack and Thiel, 1985).

The college athletics case studies highlighted above set the stage for our essay on current education, governance, business and legal issues within college athletics. This essay will build on theories of role conflict with student-athletes, synthesize the challenges, opportunities and disconnects involving leaders within college athletics, and examine current discourse related to the governance and business of college sport along with the impact this discourse has on student-athletes and policy decisions. Finally, our essay will offer practical, "real-time" solutions and articulate how student-athletes would benefit from a shift in the unrelenting discourse from hyper-commercialization (see, for example, Sperber, 1990) to innovative best practices that empower student-athletes in revenue and nonrevenue sports to optimize and use all the skill sets they have developed from competing in the classroom and in athletics. We believe this approach is beneficial to the career development realities that every student-athlete will face when they transition from college (see 
Comeaux, 2013, for a discussion of innovative career-transition strategies for college athletics departments).

\section{Student-Athlete Role Conflict}

Nick Saban, head football coach at the University of Alabama, recently commented, "all players here want to play, and they know they can't practice or play unless they do what they're supposed to do in school." He then added, "I hope they all want to go to school, but I know they all want to play ... I can really get our players to do academically what I want them to do more easily than what I could get my own kids to do" (Wolverton, 2014). Role conflict occurs when people receive contradictory demands from varied role senders, or when the roles from one status conflict with those required from another (Kahn et al., 1964). As demonstrated by the Nick Saban quote, student-athletes may experience role conflict in terms of facing difficulty balancing academic and athletic identities/roles, especially when education is framed as a separate, secondary role that solely functions as a means for a student-athlete to maintain athletic eligibility.

In one of the formative empirical studies on role conflict in college athletics, Sack and Thiel (1985) found that student-athletes are more likely to experience role conflict in situations where coaches make demands on their time and energy that prevent them from being top students. In another leading theoretical and empirical study on student-athlete identity, Settles et al. (2002) found that "interference between the demands of being an athlete and the demands of being a student was associated with some level of distress" (p. 580). Lewis (2010) critiques the college athletics model and echoes the analyses of Sack and Thiel (1985) and Settles et al. (2002) that role conflict is a reality for today's student-athlete: "Academics and education is a myth, a lie. In fact, academics is often competing for the time of athletes involved in revenue-producing athletics like football and basketball. Unfortunately school often comes second because the stakes are high" (p. 148).

Applying role conflict theory to the current landscape of college athletics is an appropriate window to view student-athlete challenges and barriers to success. Specific to FBS football and Division I men's basketball, the strain on the academic, athletic and social identities of today's male student-athletes is intense. Recruiting, required practices and training sessions, media interviews, classes and study hall sessions are a few of the major constructs that student-athletes must balance in a world where time management is perhaps a philosophic myth with all the simultaneous pressures that these student-athletes face. To echo the thoughts of renowned sports sociologist Dr. Harry Edwards, the current experiences of many student-athletes who participate in football and men's basketball (i.e., the canaries in the "goal mines") reveal numerous challenges and opportunities associated with the current collegiate athletics model.

\section{Current College Athletics Governance, Legal and Business Challenges / Opportunities}

The next few years will be a pivotal time in the history of collegiate athletics. Several NCAA member institutions are currently dealing with serious academic 
fraud situations. For example, an extensive report released in October 2014 concluded that the University of North Carolina at Chapel Hill (UNC) developed and operated a "shadow curriculum" that offered "paper classes" (i.e., courses with no class meetings or faculty involvement) over a period of almost 20 years (Wainstein, Jay, and Kukowski, 2014, p. 3). NCAA President Mark Emmert described the facts detailed in the report as "shocking and deplorable" (Wolken, 2014). Within weeks of the academic fraud report being released, a class action lawsuit was filed against UNC on behalf of former football student-athletes. The complaint alleges that UNC "systemically funneled its football student-athletes into a "shadow curriculum", and failed to provide its student-athletes with a legitimate education (McAdoo v. UNC, 2014, pp. 1-2).

In addition, the NCAA and its member conferences are currently defending numerous lawsuits that involve issues such as increasing economic support for student-athletes, guaranteeing multiyear athletics scholarships, providing enhanced medical insurance coverage and improving player safety protocols, classifying student-athletes as employees, and sharing revenue from media rights and other licensing deals with student-athletes. For instance, a judge recently determined that the NCAA must allow its member schools to offer FBS football and Division I men's basketball student-athletes a share of the revenues generated from the use of their names, images and likenesses (e.g., media rights deal for March Madness basketball tournament) in addition to offering student-athletes increased economic support that equates to a full grant-in-aid (O'Bannon v. NCAA, 2014). The NCAA is appealing this decision. Another class action lawsuit is attempting to create a free compensation market in which athletics departments would be permitted to individually negotiate "remuneration" (e.g., payments/compensation beyond athletic scholarship) and other benefits with FBS football and Division I men's basketball student-athletes (Jenkins v. NCAA, 2014).

Emmert commented that "[t]here are a couple of cases out there that are complete existential threats to college sports. If challengers succeed in creating a world where college players can be paid, it's the end of college sports as we know it" (Terlep, 2014). Yes, current academic integrity scandals and legal challenges will likely result in changes to the NCAA governance and business model, and might indeed "end college sports as we know it." But, these governance and legal issues will likely not end college sports but rather will simply result in increased economic support for student-athletes and a reshifting of priorities for the NCAA, some conferences and many athletics programs. It is important to note that some of the above-mentioned legal issues either exclusively or primarily involve only those student-athletes who participate in men's basketball or football (i.e., revenuegenerating sports). The perspective and priorities of all other student-athletes who participate in intercollegiate athletics gets lost in this discussion. We maintain the NCAA is spending too much time and money on responding to governance and legal issues instead of investing more resources into student-athlete career development as well as marketing and branding the academic achievements of student-athletes.

The NCAA continues to focus on oftentimes-reactive reform efforts instead of focusing on truly transforming its governance structure, rules and regulations, and business model so that colleges and universities are able to more effectively prepare student-athletes both academically and professionally. Reforms are usually implemented to create an outcome that will fix a problem (for example, legal 
challenges and perceived lack of emphasis on student-athlete academic success). Transforming the culture and process can prevent future problems and perhaps eliminate the need for reform initiatives. For example, when the NCAA recently reported that student-athletes who entered college in 2006 graduated at a record rate of $82 \%$, Emmert explained that the NCAA is "gratified to see our reform efforts impact the lives of those we serve" (Hosick, 2014b). Although this is encouraging news on graduation rates based on an NCAA reform initiative (i.e., outcome), much more needs to be done to transform the student-athlete educational experience so that more student-athletes are prepared for life after participating in college athletics (i.e., culture and process; see also Cunningham, 2012).

Also, in recent months conferences such as the Big Ten and Pac-12 announced adoption of student-athlete reforms that will purportedly guarantee multiyear athletic scholarships, allow former student-athletes to return to campus to complete their degree, provide enhanced medical support, and create additional rule and policy changes aimed at improving student-athlete wellbeing. Once again, while all of these reform efforts should improve the student-athlete experience, we question whether the conferences would be making these changes absent all of the current pending lawsuits facing the NCAA and its member conferences combined with intense public pressure from members of the media, scholars and other stakeholders. We also ask whether all of the above-mentioned planned reforms should have already been realities.

Some of the planned conference-level reforms are arguably ambiguous and unclear. For instance, the Big Ten conference issued a press release explaining that a student-athlete's scholarship "will neither be reduced nor cancelled provided he or she remains a member in good standing with the community, the university and the athletics department" and that "[i]f a student-athlete's pursuit of an undergraduate degree is interrupted for a bona fide reason, that student-athlete may return to the institution at any time to complete his or her degree with the assistance of an athletic scholarship" (Big Ten Conference, 2014). However, the Big Ten provides little guidance on what "good standing" means and what a "bona fide reason" entails. This new Big Ten conference policy will likely lead to confusion and potential future challenges by current and former student-athletes who contest the "good standing" and "bona fide reason" qualifiers. In addition to planned reforms at the conference level, the NCAA is currently in the process of redesigning its governance structure at the Division I level.

Planned changes include structural changes related to the size, composition and function of the board of directors and other NCAA decision-making groups as well as granting athletics programs in the "Power 5" conferences with more autonomy related to rules that impact student-athlete wellbeing. The Executive Summary of the recommended governance model proposed by the Division I Steering Committee on Governance acknowledges that:

the proposed model contains elements that range from relatively noncontroversial items to concepts that may be more complex.... Beyond the primarily structural changes proposed by the Steering Committee, it is also envisioned that additional process and culture changes will further enhance the division's ability to meet membership needs and navigate future challenges (NCAA, 2014, p. 5). 
The Steering Committee acknowledges that the new governance structure does not completely address needed process and culture changes, and that some components of the proposal are controversial and/or potentially overly complex (which may end up meaning unclear and/or unenforceable). While this proposed new governance model is a step in the right direction, it will not address or resolve many of the most pressing challenges and opportunities in college athletics.

For example, one of the three primary "unifying principles" of the new governance structure is to continue "revenue distributions as they currently exist" (NCAA, 2014, p. 36). The NCAA distributes revenue to its member institutions based on three factors. The number of athletic scholarships and the number of NCAAsponsored sports are two factors that impact the amount of revenue an athletics program receives from the NCAA. The third factor, which resulted in the largest NCAA distribution of over \$193 million in 2013-14 (i.e., 39\% of total distributed revenue), relates to the performance of all teams in each conference in the NCAA Division I men's basketball tournament over a six-year rolling period (NCAA Revenue Distribution Plan, 2014). One possible rationale why the NCAA revenue distribution formula heavily emphasizes wins in the March Madness tournament is that each year approximately $80-90 \%$ of all money generated by the NCAA is from its 14-year, $\$ 10.8$ billion contract with Turner Broadcasting and CBS for media rights to the men's basketball tournament (see NCAA Financials, 2013). Advocacy groups, such as the Knight Commission on Intercollegiate Athletics, have examined some of the problematic incentives created by the NCAA revenue distribution formula, and have proposed changes to the current NCAA three-factor formula that would in part "prioritize educational values over winning" (Knight Commission, 2010, p. 15).

Several universities have recently created policies and programming that attempt to emphasize academics and career planning. For example, bonuses to coaches and the athletics director at the University of Maryland will be linked to student-athlete Academic Progress Rate (APR) scores. This is a start. But, a focus on grades and graduating (that is, meeting the minimum requirements) is different from a focus on the development of transferable skill sets that prepare studentathletes for career success (Fields, 2012). The NCAA and its member institutions need to devote more time and financial resources toward helping student-athletes gain practical industry experience and developing proficiencies that are marketable to employers. The University of Central Florida (UCF) is an example of an athletics program that is developing innovative and practical career and professional development programs for current and former student-athletes.

UCF is in the process of developing its new Wayne Densch Center for StudentAthlete Leadership. UCF Athletics also recently launched its "Varsity Knights" initiative. The term "Varsity Knights" refers to former UCF student-athletes who have earned a varsity letter. Primary functions and components of the Varsity Knights program include business networking, career and professional development, mentoring, and community service. For example, current student-athletes will participate in "Networking Knights" with Varsity Knights and local business leaders, and current student-athletes will be assigned a Varsity Knight mentor. Todd Stansbury, UCF Vice President and Director of Athletics, explained that the goal of Varsity Knights is "to build relationships with business professionals in the community and help provide more opportunities and mentoring for student-athletes. 
This will help in career development and will also allow a platform to educate our student-athletes about what it takes to be a business professional" (UCF Varsity Knights, 2014). Stansbury also understands the importance of defining athletic program success in part based on what student-athletes do after graduation. As a result, UCF is now tracking its student-athletes five years after they graduate. These statistics will allow UCF to make data-driven decisions with respect to future programming and focus areas. In a recent feature article in Pegasus, the University of Central Florida school magazine, Kimya Massey, Director of Academic Services for Student-Athletes, commented that UCF is:

way past the point of wanting our student-athletes to just get degrees. We believe that if you're coming here to UCF, you're coming for a holistic experience. It's not just athletically or academically, but rather an experience that hopefully makes you stronger, a better person and prepared for life after college (Culture Shift, 2014, p. 29).

\section{Practical Recommendations: Creating an "Athletes Think" Identity Model}

NCAA President Mark Emmert appears to understand the importance of the studentathlete educational experience. In an October 2014 interview, Emmert issued the following comment on the recent academic fraud scandal at the University of North Carolina: "the single most important function of a university besides safeguarding people is educating them. That's why they exist. We certainly need to make sure that we're not talking about just graduating or just maintaining eligibility but educating young men and women" (Wolken, 2014). Yet, in another October 2014 interview, Emmert commented on the inability of the NCAA to develop and implement new rules, policies and processes that would improve the student-athlete athletic and academic experience, as he explained that "[y]ou can't always execute because of the political complexity of it" (Terlep, 2014). There is no excuse for this excuse. The NCAA and individual athletics programs have the ability to reduce student-athlete role conflict by creating practical, sustainable and meaningful changes that focus on the academic identity of student-athletes while also simultaneously developing a student-athlete's athletic identity (see Kissinger \& Miller, 2009).

The current collegiate athletics system is broken, and innovative approaches will be key in shifting the focus and culture of collegiate athletics. A "pay-for-play" model is not the best strategy or solution. In addition to potential legal and logistical obstacles related to implementing a pay-for-play model, financial obstacles exist - the vast majority of college athletics departments would operate at a loss if these departments did not receive subsidies each year in the form of student fees, government support, and/or institutional support. While the NCAA reported revenue of over \$912 million, expenses of approximately \$852 million, and total NCAA net assets of over $\$ 627$ million for the fiscal year ended August 31, 2013, athletics department annual expenses typically exceed revenue at over $95 \%$ of all NCAA member institutions. For example, in 2013 "expenses exceeded generated revenue at all but 20 schools in the Football Bowl Subdivision. The average loss among the five highest-resource conferences was $\$ 2.3$ million, but was much higher- $-\$ 17.6$ 
million-at all other FBS schools" (Burnsed, 2014; see also NCAA Division I Intercollegiate Athletics Programs Report, 2014).

Instead of spending so much time and money defending its "collegiate model" (i.e., amateurism; see Southall \& Staurowsky, 2013), the NCAA should focus its efforts on developing a true "meaningful education and career preparation as compensation" model. Student-athletes should be encouraged (and perhaps required) to participate in a variety of experiential learning opportunities such as attending and presenting at industry conferences as well as participating in practical internship/ apprenticeship programs with local organizations related to each student's area of career interest so that student-athletes are able to effectively leverage "access through athletics" into a successful professional career beyond the playing field or court. For example, the NCAA and its member institutions could create "academic performance competitions" such as entrepreneurship-based accelerator programs that would provide startup funding for viable business concepts developed by student-athletes. Other practical initiatives include recognizing student-athlete academic success with a helmet sticker or jersey patch (see, for example, the culturally relevant initiative at Arizona State University for a best practices model) as well as developing an interactive website/forum where current and former student-athletes are able to discuss and collaborate on academic and career-related items.

Dr. John Gerdy's ideas from the late 1990s could guide us in the right direction of creating a culture of intellectual recognition and career engagement in addition to athletic prowess with the ultimate goal of reducing the potential for role conflict. The following is one of the practical initiatives proposed by Gerdy (1997) related to emphasizing academic excellence of student-athletes:

Perhaps higher education leaders could also negotiate for increased influence in the selection and training of game announcers to ensure that they have some understanding of the goals and mission of higher education, and not solely the dynamics of the forward pass or jump shot. 'Player of the Game' features should be eliminated in favor of segments that highlight student-athletes' accomplishments off the field (p. 117).

Collaboration by all stakeholders will be key as we work together to create a new "athletes think ${ }^{\circledR}$ " model in college sport.

\section{References}

Big Ten Conference (2014). Big Ten acts to support student-athlete graduation [Press release]. Retrieved from http://btn.com/2014/10/08/big-ten-acts-to-support-studentathlete-graduation/.

Binding Consent Decree imposed by the National Collegiate Athletic Association and accepted by the Pennsylvania State University (2012). Retrieved from http:// s3.amazonaws.com/ncaa/files/20120723/21207236PDF.pdf.

Burnsed, B. (2014). Growth in Division I athletics expenses outpaces revenue increases. NCAA.org. Retrieved from http://www.ncaa.org/about/resources/media-center/news/ growth-division-i-athletics-expenses-outpaces-revenue-increases.

Comeaux, E. (2013). Rethinking academic reform and encouraging organizational innovation: Implications for stakeholder management in college sports. Innovative Higher Education, 38(4), 281-293. doi:10.1007/s10755-012-9240-1 
Corbett v. NCAA (2013). Complaint. United States District Court, Middle District of Pennsylvania.

Corman v. NCAA (2014). Senator Jake Corman's response to NCAA's supplemental 'statement' regarding documents still in dispute. Commonwealth Court of Pennsylvania.

Cunningham, G.B. (2012). Diversity and academic reform. Journal of Intercollegiate Sport, 5, 54-59.

Fields, S.K. (2012). Are we asking the right questions? A response to the academic reforms research the NCAA. Journal of Intercollegiate Sport, 5, 60-64.

Gerdy, J. (1997). The successful college athletic program: The new standard. Oryx Press.

Hosick, M.B. (2014a). Executive Committee restores Penn State football postseason, scholarships. NCAA.org. Retrieved from http://www.ncaa.org/about/resources/media-center/ news/executive-committee-restores-penn-state-football-postseason-scholarships.

Hosick, M.B. (2014b). Division I student-athletes make the grade. NCAA.org. Retrieved from http://www.ncaa.org/about/resources/media-center/news/division-i-studentathletes-make-grade.

Jenkins v. NCAA (2014). Complaint and jury demand—class action seeking injunction and individual damages. United States District Court, District of New Jersey.

Kahn, R.L., Wolfe, D.M., Quinn, R.P., Snoek, J.D., \& Rosenthal, R.A. (1964). Occupational stress: Studies in role conflict and ambiguity. New York: John Wiley.

Kissinger, D., \& Miller, M. (2009). College student-athletes: Challenges, opportunities, and policy implications. Information Age Publishing.

Knight Commission on Intercollegiate Athletics. (2010). Restoring the balance: Dollars, values and the future of college sports. Miami, Florida.

Lewis, T. (2010). Ballers of the new school: Race and sports in America. Third World Press.

McAdoo v. University of North Carolina at Chapel Hill (2014). Class action complaint. United States District Court for the Middle District of North Carolina.

Mitchell, G. (2014). Second annual report of the independent athletics integrity monitor pursuant to the athletics integrity agreement among the National Collegiate Athletic Association, the Big Ten Conference and The Pennsylvania State University and as external monitor appointed by The Pennsylvania State University. DLA PIPER LLP.

National Collegiate Athletic Association. (2014). NCAA responds to release of emails in Corman case [Press release]. Retrieved from http://www.ncaa.org/about/resources/ media-center/news/ncaa-responds-release-emails-corman-case.

National Collegiate Athletic Association. (2014). NCAA Division I Steering Committee on Governance report to Division I Board. Indianapolis, Indiana.

National Collegiate Athletic Association. (2014). 2013-14 Division I revenue distribution plan. Indianapolis, Indiana.

National Collegiate Athletic Association. (2014). NCAA Division I intercollegiate athletics program report. Indianapolis, Indiana.

National Collegiate Athletic Association. (2013). NCAA launches external review of enforcement program [Press release]. Retrieved from http://www.ncaa.org/about/resources/ media-center/news/ncaa-launches-external-review-enforcement-program.

National Collegiate Athletic Association and Subsidiaries. (2013). Consolidated financial statement as of and for the years ended August 31, 2013 and 2012. Indianapolis, Indiana.

Notice of Appeal of Consent Decree imposed upon The Pennsylvania State University (2012). Retrieved from http://espn.go.com/pdf/2012/0806/PSU_trustee_appeal.pdf.

O'Bannon v. NCAA (2014). Findings of fact and conclusions of law. United States District Court for the Northern District of California.

Sack, A., \& Thiel, R. (1985). College basketball and role conflict: A national survey. Sociology of Sport Journal, 2, 195-209.

Settles, I.H., Sellers, R.M., \& Damas, A., Jr. (2002). One role or two? The function of psychological separation in role conflict. The Journal of Applied Psychology, 87(3), 574-582. PubMed doi:10.1037/0021-9010.87.3.574 
Southall, R., \& Staurowsky, E. (2013). Cheering on the collegiate model: Creating, disseminating, and imbedding the NCAA's redefinition of amateurism. Journal of Sport and Social Issues, 37(4), 403-429. doi:10.1177/0193723513498606

Sperber, M. (1990). College Sports, Inc.: The athletic department vs. the university. Henry Holt \& Co.

Terlep, S. (2014). Inside the doors of the NCAA: Pressure is building for college sports' governing body to modernize its rules. The Wall Street Journal. Retrieved from http:// online.wsj.com/articles/inside-the-doors-of-the-ncaa-1414187475.

The Pennsylvania State University (2014). Statement from Penn State officials related to public release of internal NCAA emails discussing proposed sanctions against Penn State [Press release].

The Pennsylvania State University. (2012). Penn State President Erickson's Statement regarding NCAA Consent Decree [Press release]. Retrieved from http://progress.psu. edu/resource-library/story/penn-state-president-ericksons-statement-regarding-ncaaconsent-decree.

University of Central Florida. (2014). Culture shift: Debunking the myths of student-athlete academic standards. Pegasus. Retrieved from http://www.ucf.edu/pegasus/culture-shift/.

University of Central Florida. (2014). UCF Varsity Knights. UCF Golden Knights Club. Retrieved from http://ucfgoldenknightsclub.com/programs/varsity-knights/.

Wainstein, K.L., Jay, A.J., \& Kukowski, C.D. (2014). Investigation of irregular classes in the Department of African and Afro-American Studies at the University of North Carolina at Chapel Hill. Cadwalader. Wickersham \& Taft LLP.

Wainstein, K., . . .. (2013). Report on the NCAA's engagement of a source's counsel and use of the bankruptcy process in its University of Miami investigation. Cadwalader, Wickersham \& Taft LLP.

Wolken, D. (2014). In spite of UNC scandal, Mark Emmert cites Graduation Success Rate progress. USA TODAY Sports. Retrieved from http://www.usatoday.com/story/sports/ college/2014/10/28/ncaa-mark-emmert-graduation-success-rate-gsr-north-carolinaacademic-fraud/18053445/.

Wolverton, B. (2014). NCAA's graduate rates don't necessarily prove success. The Chronicle of Higher Education. Retrieved from http://chronicle.com/article/NCAAs-GraduationRates-Dont/149627/. 